\title{
Learning Management Systems Adoption Conundrums; Technological and Pedagogical Dilemmas that arise for Higher Education
}

\author{
Terrill Reid McLain, MBA (Corresponding Author) \\ Hankuk University of Foreign Studies \\ Assistant Professor, Global Business and Technology \\ 89 Wangsan-ri, Mohyeon-myeon, Cheoin-gu Yongin-si, Gyeonggi-do \\ E-mail: reidmclain@hufs.ac.kr
}

Received: August 4, 2017 Accepted: August 26, $2017 \quad$ Published: August 26, 2017

doi:10.5296/jet.v4i2.11646 URL: http://dx.doi.org/10.5296/jet.v4i2.11646

\begin{abstract}
Technology is used in many higher learning institutions for a multitude of reasons including distributing learning materials, organizing group projects, calculating grades, facilitating online discussions, turning in homework, creating class content, etc. When these separate technologies merge in one place, it is called a Learning Management System (LMS). Implementing an LMS in Higher Education can enhance a learning environment and assist in deploying pedagogy in a positive and efficient way while engaging students. However, there are dilemmas that arise that can hinder the solution that the technology seeks to solve. This paper discusses the divides created by the pedagogical and technological interests of LMS adoption in higher education and outlines future research needed for more successful implementation and subsequent continued use. In a sea of options, the solutions that are strongest include individual customization flexibility and have strong peer support; these are the ones that seem to last.
\end{abstract}

Keywords: LMS, Learning Management Systems, Pedagogy, EdTech, Educational Technology, Technology Adaptation, Higher Education

\section{Background}

Technology use in education with tools combined in learning management systems (LMS) is commonplace in Higher Education (Almarashdeh, 2016) There are many types of separate technology that can satisfy diverse learning, pedagogical, and organizational needs for instructors in Higher Education. The (LMS) is the combination of all these separate technology systems and learning resources in one place. It is a grade book, assignment distributor, assignment collector, grade giver, attendance taker, conversation facilitator, collaboration tool, instant messaging platform, e-mail client, and more all in one. Kasim et al. 
note that "Learning Management Systems represent an evolution from the processes and systems developed by certain institutions to register students on specific courses and keep records of students' activities." (Kasim \& Khalid, 2016) A recent article in PC Mag also points out, that many universities, business and organizations are now using them to meet educational goals. (Fenton, 2017) Therefore, confirming that higher education institutions have directives for these resources to be set up and implemented. With all of this help developed to assist learning and help the students and teachers, why then do instructors hate their LMS? David Wentworth of the Brandon Hall Group does an annual study on employee LMS satisfaction; In 2014 they found that " $47.7 \%$ of respondents are looking to leave their current LMS platform and move to a new provider." (PR Web Newswire, 2014)These chosen LMS systems are generally robust and appear to solve the abundance of time consuming and ordinary administrative tasks to free up the educator, placing the focus where it should be; students learning and engagement. However, challenges emerge when the technology is incompatible with the purposes of an instructor's pedagogy and teaching style culminating in the teacher abandoning or under using the resource.

The 2017 NCM Horizon Report for Higher Education, an annual study for educational technology, lists the current challenges for technology adoption for post graduate education; they divide the challenges into three categories solvable, difficult and 'wicked' (Consortium, 2017). The solvable challenges, easy to define and solve; the difficult challenges, easy to define but solution is difficult; and 'wicked' challenges, complex in both definition and solution. (Consortium, 2017) The conundrums of this paper are similar to the "wicked challenges' as noted in the Consortium. The conundrums outlined concern the dilemmas of technology adoption and pedagogical adoption

\section{Current technology integration research}

The technology acceptance module developed by Davis in 1989 established the acceptance criteria focusing on the user perceptions differentiating between the perceived ease of use and perceived usefulness. (Davis, 1989) A closer examination of the current technology divide research enhances this module further. It suggests that technology use and adoption in companies does not equate to a flow from technology to adoption and continued use. (Lanzolla \& Suarez, 2012) The main idea of LMS adoption is to integrate technology into the workflow to help teaching, learning, classroom management and institution administration and for it to be used on a continued basis. However, managing the different resources can become a burden for an educator if there are too many - even more if the sources are diverse with a high learning curve and do not match an educator's individual learning style. At their worst, they become obsolete. This is essential because an instructor's satisfaction concerning the technology being used is vital to the success of the implementation. (Almarashdeh, 2016) There are two areas where instructors find the challenge; one is the dilemma of obsolescence and the other is the dilemma of pedagogical adaptation.

\section{The obsolescence dilemma}

LMS systems are designed to fit the needs and desires of the team-administration, educators, and students - and systems are purchased or developed in house to help student learning. 
These desires and abilities fall along the spectrum of the diffusion of innovation from early adopters to laggards. (see Rogers, 2010) However, after adoption, instructors and students may find roadblocks for certain tasks and classroom essentials and either reduce the use or stop using the system. As cited in Lanzolla "this practice is so common in software that the business press has coined the phrase "shelfware"-software that, once purchased, is put on a shelf and never used," (Lanzolla \& Suarez, 2012) very similar to an app on a smartphone that is downloaded with the intent to use, but in practice becomes wasted space on the smartphone, and eventually deleted. There also can be the problem of home grown solutions; "homegrown LMSs can be more than 20 years old, suggesting that schools with these systems have an additional institutional inertia to overcome in order to endure the pain of a migration to a new system." (MindWires LLC, 2017, p. 6) The dilemma here is, even if an LMS implementation appears to solve technological and pedagogical needs, there is still a chance that the technology may not be used later and becomes a wasted resource. (Lanzolla \& Suarez, 2012 page 843) The converse of that is, if an instructor becomes dependent on a system and that technology becomes obsolete, as homegrown systems sometimes do, they have to go through the technology adaptation cycle all over again(West, Waddoups, \& Graham, 2006) 'You also have to balance as a teacher how much time you spend on things ... how much time the technology is going to cost you. It does take time," (West et al., 2006, p. 15) Once an instructor takes the time to adapt to the technology they become dependent on it and even though it doesn't work $100 \%$ for them they still use it in spite of other emerging technologies that could help them better; they do not have time to try out all the available resources. (West et al., 2006)

A recent report from the Educause Center for Analysis and Research (ECAR) notes that it is expensive and complex for institutions to replace existing LMS systems. (Lang \& Pirani, 2016) Nevertheless, the LMS and other technology that a university may use is in continually in danger of becoming obsolete. According to the 2017 Horizon Report, any technology is in danger of becoming irrelevant. They note that; "another dimension of this challenge is the idea that institutions must prepare for the possibility that the technologies they adopt may be rendered obsolete by future incarnations or discontinuations." (Consortium, 2017) An example of this: In 2016 Pearson announced that they would be discontinuing their standalone LMS Product called LearningStudio. (Hill, 2016) Phil Hill noted that "like the forced migration caused by WebCT and ANGEL end-of-life notices, there will now be more than 100 LMS changes triggered by this announcement." (Hill, 2016)

\section{Staying current}

A recent EDUCAUSE case study of LMS noted that "more than 8 in 10 institutions (84\%) using a solution from one of the top 4 vendors-Blackboard, 43\%; D2L, 14\%; Instructure, 14\%; and Moodle Trust, 13\% - the learning management system market is fairly homogeneous" (Lang \& Pirani, 2016) Research shows that instructors that help each other are more likely to implement and use the systems. However if there is an ultra-competitive atmosphere or not much interaction amongst colleagues in a department, this can hinder the technology use. (West et al., 2006, p. 16) Instructors who can find resources-especially peers - outside of the school to turn to for brainstorming and problem solving are more likely to continue to use the systems. 


\section{The pedagogical innovation dilemma}

Technology does not stay the same once adopted, thus the adaptation process is cyclical and exacerbates the difficulty for users to find pedagogical solutions. (Lanzolla \& Suarez, 2012). Innovations in pedagogy come when instructors embrace technology and use it to enhance their teaching strategies. These innovations are lost as the result of minimal use, abandonment of the tool or failing to fit it into teaching practice. Research shows that students want more faculty to use these systems. (Lang \& Pirani, 2016, p. 10) When teachers are focused on student centered learning rather than teacher centered learning it is easier to push through the difficulties when faced with technology adoption. (De Smet, Valcke, Schellens, De Wever, \& Vanderlinde, 2016) In a recent blog post discussing fear of LMS technology adoption, Michael Feldstein of MindWires finds that "faculty do not want to waste students' time; they want to teach well. Using methods that they have honed is therefore important." (Feldstein, 2017) He furthers the thought by insisting that "until we change the incentives and provide alternative sources of personal identity affirmation, faculty will not be motivated to invest time and energy in changing their teaching to adopt practices shown by research to be more effective." (Feldstein, 2017)

These human centered technology dilemmas regarding pedagogy fall into two categories internal and external. (De Smet et al., 2016) The solvable barriers are external-training, support, access to internet, etc. The barriers that are much harder to change are internal teaching beliefs, practices, etc. (De Smet et al., 2016) The pedagogical dilemma is an internal barrier that can be solved if a chosen technology is adaptable and if there are resources for instructors to adapt the technology to fit their individual needs-meet their personal identity affirmation. (Matthews, 2017) In order to mitigate these internal barriers, there has to be a different level of support than just technology training.

\section{Beyond technology training; building user champions}

Dilemmas come in two waves: First when the LMS technologies advance too fast, develop slowly, stagnate, or disappear. Then when they clash with personal identity affirmation, technology training, pedagogical adaptation, and customization. These two waves of dilemmas can be solved by having a strong customer service/development team and user level LMS Champions. In customer service training, these champions are sometimes called raving fans (Blanchard, 1993). They are the users and employees that help others use the system, innovate and problem solve and cheerlead for the brand. These people will go through the trial and error, and then push through the errors because they see the LMS's value as something worthwhile for everyone - even when the system is not perfect. The premise of creating this atmosphere of user champions is to change the basic question from; How to use the technology? to How can we make this technology work for you and your style?

The recent growth of Instructure Canvas is a model of how this question shift can change the course of LMS engagement. Canvas by Instructure, a newcomer to the market in 2010, rose to a $17 \%+$ MarketShare capture by 2015. (see Lang \& Pirani, 2016, p. 7) Part of this success can be attributed to the strong activity of both their employees and end users in their active community pages. As the 2017 report from MindWires notes "in addition, they 
[Canvas] had (and still have) a reputation for ease of use and good customer service. This reputation has been enhanced by marketing that has been far more sophisticated than that of any of their competitors." (MindWires LLC, 2017, p. 13) This report also shows that the majority of the migrations to the Canvas infrastructure has been voluntary. (MindWires LLC, 2017) On the Canvas user community (https://community.canvaslms.com/) there are sections to find answers, share ideas for teaching and technology development and to join interest groups. (Canvas by Instructure, 2017) Navigating to Find Answers>All Questions there are 590 discussions and 7712 Questions with the accessible log only going back to April 15, 2015 (Canvas by Instructure, 2017) at the time of writing this paper. This shows a much more active user community as compared to the industry leader Blackboard's similar offering which only had 379 total content pieces; blog posts, discussions, polls dating back to July 20, 2015 (Blackboard Community, 2017) Navigating to Discussions $>$ Educators $>$ Content to find the similar content. This community activity combined with the excellent customer service and known ease of use, and adaptability is key for the current success of Canvas, and why the educators who embrace them continue to use the technology even as it adds new tools. As a 2014 article from Phil Hill points out; "Rather than focusing on being better than Blackboard or Desire2Learn or Moodle or Sakai, the real competition for Canvas now seems to be lack of meaningful adoption, whether the end users are working online or face-to-face." (Hill, 2014) their company aim has shifted to embrace the question; How can we make this technology work for you?

\section{Conclusion}

Technology is developing at a rapid pace and higher education needs to stay current with these trends and update their LMS technologies to stay relevant. While the tools are dynamic and ever-changing; it is important to find tools that have an existing framework of user champions and the technology be flexible enough to adjust to different user styles and affirm instructors' personal identities while remaining congruous and familiar enough for other faculty and students. Looking at the model of Canvas by Instructure to see what the demand wave is will help guide these decisions. The "selection of a learning management system (LMS) is an important decision that should involve multiple internal stakeholders." (Lang \& Pirani, 2016) one person or a small committed team are not enough to make a lasting decision. More complex research needs to be done at all levels of adaptation for higher education pedagogy in relation to educational technology and learning management systems. These studies need to follow users over a period, rather than a snapshot of feelings in time, will help the understanding of what happens after adoption. (Lanzolla \& Suarez, 2012) It is also important to continue to follow the LMS market and watch for the changes as new leaders emerge. The end goal to have institutions work on making the chosen technology work for instructors and students, rather than the other way around.

\section{Acknowledgement}

This work was supported by Hankuk University of Foreign Studies Research Fund of 2017 


\section{References}

Almarashdeh, I. (2016). Sharing instructors experience of learning management system: A technology perspective of user satisfaction in distance learning course. Computers in Human Behavior, 63, 249-255. http://doi.org/10.1016/j.chb.2016.05.013

Blackboard Community. (2017). Educator Community | Blackboard Community. Retrieved July 31, 2017, from https://community.blackboard.com/community/questions/educator/ content?browseSite $=$ content $\&$ browseViewID $=$ placeContent $\&$ userID $=2003 \&$ containerType $=$ $14 \&$ containerID $=2059 \&$ filterID $=$ contentstatus $\% 5$ B published $\% 5 \mathrm{D} \sim$ objecttype $\sim$ showall\&sort Key $=$ contentstatus $\% 5$ Bpublished $\% 5 \mathrm{D} \sim$ creationDateAsc \&sortOrder $=1$

Blanchard, K. (1993). Raving Fans. New York, NY: William Morrow.

Canvas by Instructure. (2017). Canvas Community. Retrieved August 1, 2017, from https://community.canvaslms.com/

Consortium. (2017). Horizon Report Higher Education (Edition 2017, pp. 1-60).

Davis, F. D. (1989). Perceived usefulness, perceived ease of use, and user acceptance of information technology. MIS Quarterly, 13(3), 319. http://doi.org/10.2307/249008

De Smet, C., Valcke, M., Schellens, T., De Wever, B., \& Vanderlinde, R. (2016). A qualitative study on learning and teaching with learning paths in a learning management system. JSSE Journal of Social Science Education, 15(1), 27-37. http://doi.org/10.2390/jsse-v15-i1-1460

Feldstein, M. (2017, July 19). Fear Itself. Retrieved August 2, 2017, from http://mfeldstein.com/fear-itself/

Fenton, W. (2017, March 28). The Best LMS (Learning Management Systems) of 2017. Retrieved July 20, 2017, from https://www.pcmag.com/article2/0,2817,2488347,00.asp

Hill, P. (2014, June 19). InstructureCon: Canvas LMS has different competition now. Retrieved July 31, 2017, from http://mfeldstein.com/instructurecon-canvas-different -competition-now/

Hill, P. (2016, February 1). LearningStudio and OpenClass End-Of-Life: Pearson is getting out of LMS market. Retrieved August 2, 2017, from http://mfeldstein.com/learningstudio -openclass-end-life-pearson-getting-lms-market/

Kasim, N. N. M., \& Khalid, F. (2016). Choosing the right learning management system (lms) for the higher education institution context: a systematic review. International Journal of Emerging Technologies in Learning (iJET), 11(06), 55-61. http://doi.org/10.3991/ijet.v11i06. 5644

Lang, L., \& Pirani, J. A. (2016). The 2015 Enterprise Application Market in Higher Education: Learning Management Systems. Louisville, CO: EDUCAUSE.

Lanzolla, G., \& Suarez, F. F. (2012). Closing the technology adoption-use divide. Journal of Management, 38(3), 836-859. http://doi.org/10.1177/0149206310369938 


\section{Macrothink}

Matthews, D. (2017, July 6). Fear of Looking Stupid. Retrieved August 3, 2017, from https://www.insidehighered.com/news/2017/07/06/anthropologist-studies-why-professors-do nt-adopt-innovative-teaching-methods

MindWires LLC. (2017). LMS Market Historical Perspective (Vol. 2017, pp. 1-26). MindWires LLC. Retrieved from http://mfeldstein.com

PR Web Newswire. (2014). New Brandon Hall Group Report Tracks LMS Satisfaction and Spending Trends. Retrieved July 22, 2017, from http://www.prweb.com/releases/2014/02/ prweb11557969.htm

Rogers, E. M. (2010). Diffusion of Innovations, 4th Edition. Simon and Schuster.

West, R. E., Waddoups, G., \& Graham, C. R. (2006). Understanding the experiences of instructors as they adopt a course management system. Educational Technology Research and Development, 55(1), 1-26. http://doi.org/10.1007/s11423-006-9018-1

\section{Copyright Disclaimer}

Copyright reserved by the author(s).

This article is an open-access article distributed under the terms and conditions of the Creative Commons Attribution license (http://creativecommons.org/licenses/by/3.0/). 